\title{
Enterotoxin production by Staphylococcus aureus isolates from cases of septicaemia and from healthy carriers
}

\author{
H. HUMPHREYS*, C. T.KEANE, ROSEMARY HONE‡, HARRIETT POMEROY†, R. J. \\ RUSSELLt, J.P.ARBUTHNOTTt and D.C. COLEMANT§
}

Department of Clinical Microbiology. St James's Hospital, Dublin 8, †Moyne Institute, Department of Microbiology, Trinity College, Dublin 2, and $¥$ Department of Microbiology, The Mater Misericordiae Hospital, Dublin 9, Ireland

\begin{abstract}
Summary. In a prospective study, 52 Staphylococcus aureus isolates from individual patients with septicaemia and 27 nasal strains from separate, healthy carriers were compared for production of a range of extracellular proteins and toxins. Whereas there was no difference $(p>0.05)$ between septicaemic and nasal isolates with respect to incidence of $\alpha, \beta, \gamma$ and $\delta$ haemolysins, toxic shock syndrome toxin-1 or staphylokinase production, the incidence of enterotoxin $\mathrm{A}, \mathrm{B}$, and $\mathrm{C}$ production was higher among isolates from septicaemia $(p<0.01)$. Of the isolates from septicaemia, $33(63 \%)$ produced enterotoxins A, B, C or D alone or in combination. Only three $(11 \%)$ of the nasal isolates produced a single enterotoxin, enterotoxin D. Of the isolates from septicaemia, $67 \%$ were hospital-acquired and $>25 \%$ of these were endemic, methicillin-resistant (MRSA) strains. All MRSA strains produced either enterotoxin $\mathrm{A}$, or enterotoxin $\mathrm{B}$, or both. These findings suggest a possible role for enterotoxins in the pathogenesis of $S$. aureus disease other than food poisoning.
\end{abstract}

\section{Introduction}

Staphylococcus aureus is a common cause of serious hospital infection and ranks second to Escherichia coli as the causative agent of clinically significant septicaemia (Maki, 1981; Gemmell, 1984; Lacey et al., 1984). Septicaemia is one of the most serious infections caused by $S$. aureus, but little is known about the basic characteristics of the strains responsible. Despite appropriate chemotherapy, mortality in cases of septicaemia is in the range $20-30 \%$ (Nolan and Beaty, 1976; Shah and Watanakunakorn, 1979).

$S$. aureus strains can produce a considerable range of extracellular proteins and toxins (Freer and Arbuthnott, 1972; Arvidson, 1983), some of which are particularly important in specific diseases such as toxic shock syndrome, scalded skin syndrome and staphylococcal food poisoning (Arbuthnott, 1983, 1988; Bergdoll, 1983). Apart from these diseases, the precise contribution of individual extracellular proteins to the pathogenesis of infec-

Received 24 Mar. 1988; accepted 12 June 1988.

*Present address: Department of Microbiology, Bristol Royal Infirmary, Bristol BS2 8HW.

$\S$ Correspondence should be addressed to Dr D. C. Coleman. tion is unclear, and it is likely that the pathogenesis of $S$. aureus disease is multifactorial.

The involvement of enterotoxins in staphylococcal food poisoning is well documented, and, recently, $S$. aureus enterotoxin $\mathrm{B}$ has been shown to be responsible for some cases of toxic shock syndrome (Crass and Bergdoll, 1986a). Although they are known to have a number of biological activities, enterotoxins have not been considered to have a role in other $S$. aureus diseases. We have examined the capacity of $52 \mathrm{~S}$. aureus isolates, from separate cases of septicaemia, to produce a range of extracellular proteins and toxins. These strains have been compared with 27 commensal isolates of $S$. aureus from healthy individuals, to determine whether isolates from septicaemia are distinct with regard to production of potential virulence factors.

\section{Materials and methods}

\section{Patients with septicaemia}

Cases of $S$. aureus septicaemia in 52 different patients were studied. Many of the patients had one or more underlying diseases, including malignancy, alcohol-related disease, endocarditis, bone or joint disease, cardiac 
conditions, burns, trauma, prematurity at birth, and postoperative trauma. Clinically significant $S$. aureus septicaemia was defined as two or more positive blood cultures accompanied by clinical evidence of septicaemia. When only a single sample was taken before antimicrobial chemotherapy, a positive culture accompanied by a pyrexia $>37.5^{\circ} \mathrm{C}$ in an appropriate clinical context constituted grounds for inclusion in the study. Septicaemia present on admission to hospital or within 3 days of admission was deemed to be community-acquired. This occurred in 17 cases, whereas in 35 cases the septicaemia was considered to be hospital-acquired. Many of the hospital-acquired septicaemias developed after instrumentation or invasive procedures. In 44 patients there was a primary focus of infection caused by $S$. aureus, which subsequently gave rise to septicaemia. This was determined on the basis of clinical studies, by phage typing of isolates from the infected site, and from subsequent blood cultures. In these cases, septicaemia was regarded as secondary. A primary septicaemia was considered to have occurred when there was no previous evidence of $S$. aureus infection. This occurred in eight patients.

Nineteen $(36.5 \%)$ of the patients with septicaemia died. None of the patients with septicaemia presented with clinical symptoms of food poisoning or toxic shock syndrome.

\section{Bacterial strains and culture media}

Fifty-two blood-culture isolates from patients with $S$. aureus septicaemia were chosen for study. These were compared with $27 \mathrm{~S}$. aureus isolates from the anterior nares of 27 separate, healthy medical students prior to their clinical attachments. Isolates were identified on the basis of positive coagulase and thermostable DNAase tests. The isolates were routinely cultured at $37^{\circ} \mathrm{C}$ for $18 \mathrm{~h}$ in Trypticase Soy Broth (TSB) (BBL, Cockeysville, $\mathrm{MD}$, USA) in an orbital shaker at $150 \mathrm{rpm}$. The corresponding agar medium was also used. For the detection of enterotoxins and toxic shock syndrome toxin1 (TSST-1), Brain Heart Infusion (BHI) Broth (Oxoid) was used in place of TSB as the growth medium. Rabbit-, sheep- and human-blood-agar plates were prepared by incorporating the respective washed erythrocytes $(5 \% \mathrm{v} / \mathrm{v})$ into Trypticase Soy Agar (TSA). Sheepblood-agar plates were also supplemented with $10 \mathrm{mM} \mathrm{MgSO}_{4}$. Agarose $1 \% \mathrm{w} / \mathrm{v}$ was used to solidify rabbit blood plates for $\gamma$-lysin assays.

\section{Chemicals and antibiotics}

Chemicals and antibiotics were purchased from the Sigma Chemical Co. (Poole, Dorset) or BDH Chemicals (Poole, Dorset).

\section{Bacteriophage typing}

Bacteriophage typing was performed as described by Blair and Williams (1961). The International Basic Set of bacteriophages for typing $S$. aureus was supplied by the Central Public Health Laboratory, Colindale, London. The septicaemia and nasal carriage isolates were divided into the phage groups I, II, III and V (Parker, 1983) on the basis of their sensitivity patterns to the Basic Set of typing phages. Isolates which were typable with phage 95 only were placed in a separate group as recommended by Parker (1983). Strains which could not be typed with the Basic Set of phages were placed in another separate group, termed the non-typable group.

\section{Staphylokinase, coagulase and DNAase tests}

$S$. aureus isolates were tested for staphylokinase production on heated plasma agar as described by Devriese and Van De Kerckhove (1980). S. aureus strain 8325-4 lysogenised with the staphylokinase-converting bacteriophage $\phi 13$ (Novick, 1967), as described by Coleman et al. (1986), was used as the control staphylokinase-producing strain. Isolates were tested for coagulase production by the tube-coagulase test with human plasma. The "Oxford" strain of $S$. aureus, NCTC 6571, was used as the positive control organism. Thermostable DNAase tests were performed with heated culture supernates on Toluidine blue agar as described by Shortle (1983).

\section{Detection of S. aureus enterotoxins and toxic shock syndrome toxin-1}

Production of $S$. aureus enterotoxins A, B, C and D, and toxic shock syndrome toxin-1 (TSST-1) was determined by reverse passive latex agglutination (RPLA), by means of kits purchased from Oxoid and used according to the manufacturer's instructions. All tests were performed in triplicate. To confirm the data obtained from the RPLA assays, $50 \%$ of the septicaemia and nasal isolates were tested for production of enterotoxins $\mathrm{A}, \mathrm{B}$, C, and D by Western immunoblotting (Burnette, 1981) with specific rabbit anti-enterotoxin sera (Russell et al., 1985) and 50-fold concentrated culture supernate proteins, as described by Coleman et al. (1986). In a similar fashion, all isolates which were TSST-1-positive (TSST$1^{+}$), as determined by RPLA assays, were re-tested for TSST-1 production by immunoblotting with specific rabbit anti-TSST-1 serum.

\section{Antisera and standard enterotoxin preparations}

Purified $S$. aureus TSST- 1 and enterotoxins A, B, C, and $D$, together with the corresponding rabbit antisera, were the generous gift of Professor M. S. Bergdoll (Food Research Institute, University of Wisconsin, Madison, USA). Rabbit antibodies raised against purified $S$. aureus haemolysins were gifts from Dr C. Adlam (Wellcome Laboratories, UK; anti- $\alpha$, anti- $\beta$ ), Dr G. Dougan and $\mathrm{Mr}$ D. Prichard, (Wellcome Laboratories, UK ; anti- $\delta$ ), and Dr T. H. Birkbeck (University of Glasgow ; anti- $\gamma$ ). 


\section{Detection of $S$. aureus haemolysins}

Production of $\alpha$-lysin by each strain was determined by laying a filter paper strip, soaked in anti- $\alpha$-lysin serum, perpendicularly across streaked inocula of the isolates on rabbit-blood agar and incubating at $37^{\circ} \mathrm{C}$ for $24 \mathrm{~h}$, followed by examination of the plates for inhibition of haemolysis. S. aureus strain Wood 46 (Kjems, 1963) was used as the control $\alpha$-lysin producing strain.

Production of $\beta$-lysin was determined by streak inoculating each strain on sheep-blood-agar plates and incubating at $37^{\circ} \mathrm{C}$ for $18 \mathrm{~h}$ followed by $4-8 \mathrm{~h}$ at $4{ }^{\circ} \mathrm{C}$; $\beta$-lysin $\left(\mathrm{a} \mathrm{Mg}^{++}\right.$-dependent sphingomyelinase $\mathrm{C}$ with a marked specificity towards sheep erythrocytes) exhibits "hot-cold" haemolysis (Möllby, 1983). Complete haemolysis develops when the plates are incubated for a short time below $10^{\circ}$ C. S. aureus strain BB (Derbyshire, 1961) was used as the control $\beta$-lysin producing strain.

Production of $\gamma$-lysin was determined by stab-inoculating each isolate in to rabbit-blood-agar and rabbit-bloodagarose plates followed by incubation at $37^{\circ} \mathrm{C}$ for $24 \mathrm{~h}$. After incubation, zones of haemolysis on both media were measured and compared. Strains which consistently yielded larger zones of haemolysis $(>4 \mathrm{~mm})$ on the agarose medium were recorded as $\gamma$-lysin-positive. $S$. aureus strain Smith 5R (Möllby, 1983) was used as the control $\gamma$-lysin-producing strain. $\gamma$-Lysin is inhibited by acid polysaccharides contained in standard laboratory agar but not by purified preparations such as agarose (Möllby, 1983; Carlson, 1986).

Production of $\delta$-lysin was detected by streaking each isolate perpendicularly to a streak of $S$. aureus strain BB on sheep-blood agar followed by incubation at $37^{\circ} \mathrm{C}$ for $24 \mathrm{~h} ; \delta$-lysin potentiates the effect of $\beta$-lysin (Möllby, 1983), and enhances the partial haemolysis of the sheep erythrocytes caused by the production of $\beta$-lysin by strain BB in the area where the haemolytic zones of the clinical isolates and strain BB overlap, resulting in areas of complete haemolysis. S. aureus strain NCTC 10345 (Kjems, 1963) was used as the control $\delta$-lysin producing control strain.

To confirm the incidence of haemolysin production determined by the methods described above, 20 septicaemia and 10 nasal isolates were tested for haemolysin production by Western immunoblotting of 100 -fold concentrated culture supernate proteins as described by Coleman et al. (1986). In the case of $\delta$-lysin, concentrated supernate proteins were separated in $15 \%$ polyacrylamide gels. Rabbit anti- $\alpha,-\beta,-\gamma$, and $-\delta$-lysin sera (diluted 1 in 100) were used as the first antibody solutions respectively. All TSST $-1^{+}$isolates and all isolates that were weakly haemolytic or non-haemolytic on rabbit-blood agar were tested for $\alpha$-lysin production by Western immunoblotting.

\section{Antibiotic susceptibility tests}

Antibiotic susceptibility tests were performed by a disk-diffusion method as described by Coleman et al. (1985). Overnight $(18 \mathrm{~h}$ ) cultures in LB broth (Oxoid) were diluted 1 in 1000 in fresh LB broth and spread on
DST agar (Oxoid) plates. Antibiotics were used at the following concentrations: penicillin G 1.5 units, ampicillin $25 \mu \mathrm{g}$, erythromycin $5 \mu \mathrm{g}$, sulphafurazole $100 \mu \mathrm{g}$, trimethroprim $1.25 \mu \mathrm{g}$, amikacin $30 \mu \mathrm{g}$, gentamicin $10 \mu \mathrm{g}$, kanamycin $10 \mu \mathrm{g}$, streptomycin $20 \mu \mathrm{g}$, spectinomycin $20 \mu \mathrm{g}$, tetracycline $10 \mu \mathrm{g}$, vancomycin $30 \mu \mathrm{g}$, fusidic acid $10 \mu \mathrm{g}$ and chloramphenicol $20 \mu \mathrm{g}$. Methicillin-resistance was tested at $30^{\circ} \mathrm{C}$ with $5-\mu \mathrm{g}$ and $10-\mu \mathrm{g}$ methicillin strips as described by Coleman et al. (1985).

\section{Statistical analysis}

Differences in the incidence of production of individual extracellular proteins between the septicaemia and nasal isolates were tested for statistical significance by Yates' $\chi^{2}$ test. A p-value of $<0.05$ was considered to indicate statistical significance (Langley, 1979a). Fisher's Test was used to calculate significant differences between the groups of septicaemia strains listed in table II (Langley, $1979 b$ ).

\section{Results}

\section{Antibiotic susceptibility and phage typing}

The majority of the septicaemia isolates expressed resistance to ampicillin and penicillin only. However, nine isolates were methicillin-resistant and were also resistant to ampicillin, penicillin, streptomycin, spectinomycin, erythromycin, gentamicin, kanamycin and sulphafurazole. Eight of these isolates were resistant to fusidic acid, and belonged to a closely related group of methicillinand gentamicin-resistant $S$. aureus strains (MRSA), termed Phenotype-II Dublin isolates, which have been endemic in Dublin hospitals for the past decade. Six of these related MRSA isolates belonged to phage-group III and two were non-typable. Two of the former and both of the latter isolates also expressed resistance to tetracycline and trimethroprim. The remaining methicillin-resistant isolate was sensitive to fusidic acid and resistant to chloramphenicol and tetracycline, and was indistinguishable from a separate group of MRSA isolates that was first detected in Dublin hospitals in June 1985 and which were unrelated to Phenotype-II Dublin strains. This isolate also belonged to the non-typable group. Most of the nasal isolates were resistant to ampicillin and penicillin, but none was resistant to methicillin or to the other antibiotics tested.

The results of phage typing the 52 septicaemia and 27 nasal isolates are shown in table I. The majority of septicaemia isolates belonged to phage- 
group III or the non-typable group, whereas most of the nasal isolates belonged to either the nontypable group or group I (table I). None of the control nasal isolates belonged to phage-group III.

\section{Production of extracellular proteins}

The pattern of production of extracellular proteins by the septicaemia and nasal isolates is shown in table I. The incidence of production of haemolysins, toxic shock syndrome toxin-1 (TSST-1) and staphylokinase by both groups of isolates was similar, and the small differences observed were not statistically significant $(\mathrm{p}>0.05)$. The frequency of $\alpha$-lysin production by phage-group I $(66.6 \%)$ and non-typable $(58 \%)$ septicaemia isolates was lower than in the other phage groups. However, these differences were not statistically significant $(p>$ 0.05 ), probably because of the relatively small numbers of isolates involved. Three of the five phage-group I TSST $-1^{+}$septicaemia isolates were $\alpha$-lysin ${ }^{-}$. All of the remaining TSST- $1^{+}$septicaemia and nasal isolates were $\alpha$-lysin ${ }^{+}$. One of the $\alpha$-lysin ${ }^{-}$, TSST $-1^{+}$septicaemia isolates was also $\gamma$-lysin ${ }^{-}$and $\delta$-lysin ${ }^{-}$and $\beta$-lysin ${ }^{+}$, whereas all the other TSST $-1^{+}$isolates were $\beta$-lysin ${ }^{-}, \gamma$-lysin ${ }^{+}$and $\delta$-lysin ${ }^{+}$. All methicillin-resistant strains were $\alpha$-lysin ${ }^{+}, \gamma$-lysin ${ }^{+}, \delta$-lysin ${ }^{+}$and staphylokinase ${ }^{+}$, but were $\beta$-lysin ${ }^{-}$and TSST- $1^{-}$.

Production of $S$. aureus enterotoxins A, B, C, or $\mathrm{D}$, alone or in combination, was detected in 33 $(63.5 \%)$ of the 52 septicaemia isolates (table I); 17 produced a single enterotoxin and 16 produced two or more. None of the nasal isolates produced enterotoxins A (SEA), B (SEB), or C (SEC) and only three isolates $(11.1 \%)$ produced enterotoxin $\mathrm{D}$ (SED; table I). When the incidence of enterotoxin production was analysed, the observed differences in production of SEA, SEB, and SEC by both groups of isolates were highly significant $(p<0.01)$. Patterns relating enterotoxin production and phage group were found among the 52 septicaemia isolates investigated (table I): (i) the only enterotoxin produced by the phage-group $\mathrm{V}$ isolates was SEB, which was produced by the majority; (ii) of the five phage-group II isolates examined, only one produced an enterotoxin; (iii) SEC was produced by the majority of phage-type 95 isolates, most of which also produced SED.

All nine methicillin-resistant septicaemia isolates produced enterotoxin; five produced SEA and SEB, two produced SEA only, and two produced SEB only. These isolates accounted for all the SEA+ SEB-positive isolates detected in this study (table I).
Properties of septicaemia strains in relation to acquisition and outcome of infection

Of the septicaemia isolates $35(67 \cdot 3 \%)$ were from cases of hospital-acquired infection and 17 were community acquired $(32.7 \%)$. Sixteen of the septicaemia patients infected with hospital-acquired organisms died, compared with only three of 17 patients infected with community-acquired strains. The majority of hospital-acquired organisms belonged to phage-group I (7 of the 9 in group I), group III ( 8 of the 13 in III) and the non-typable group (9 of the 12, non-typable septicaemia isolates). Of the community-acquired strains, $29 \%$ belonged to phage-group III; the remainder being approximately evenly distributed between the other phage groups. All of the methicillin-resistant isolates were hospital acquired.

The incidence of production by the hospital- and community-acquired septicaemia isolates of $\alpha$-lysin, $\gamma$-lysin, $\delta$-lysin, TSST-1, SEA and SEC was similar, and no statistically significant differences were recorded $(p>0.05)$. In contrast, none of the community-acquired (CA) strains produced $\beta$-lysin compared with a production frequency by the hospital acquired (HA) organisms of $12 \%$. This difference was statistically highly significant $(p<0 \cdot 01)$. Furthermore, significant differences $(p<0.01)$ were observed in the frequency of production of staphylokinase (HA 74.3\%, CA 94.1\%), SEB (HA 28.6\%, CA 6.6\%) and SED (HA $11.4 \%$, CA $35.3 \%$ ) by the hospital and community-acquired isolates.

\section{Enterotoxin production by septicaemia isolates in relation to source and outcome of infection}

The properties of all septicaemia isolates were analysed in relation to the original $S$. aureus infected focus (source), where known, and outcome of infection (table II). A $S$. aureus-infected intravascular catheter was the most frequent source of infection which subsequently gave rise to septicaemia. Seven $(87.5 \%)$ of the eight septicaemia isolates that originated from wound infections were methicillin-resistant, and these accounted for $77.8 \%$ (7 out of 9) of the total number of methicillin-resistant isolates included in the study. The highest mortality was in patients with septicaemia caused by phagegroup III isolates (table II). Of the seven septicaemia patients who were infected with these isolates and died, six were infected with methicillinresistant strains. The incidence of deaths associated with these methicillin-resistant isolates was significantly different $(p<0.01)$ from the incidence of 
Table I. Production of extracellular proteins by septicaemia and nasal carriage $S$. aureus isolates

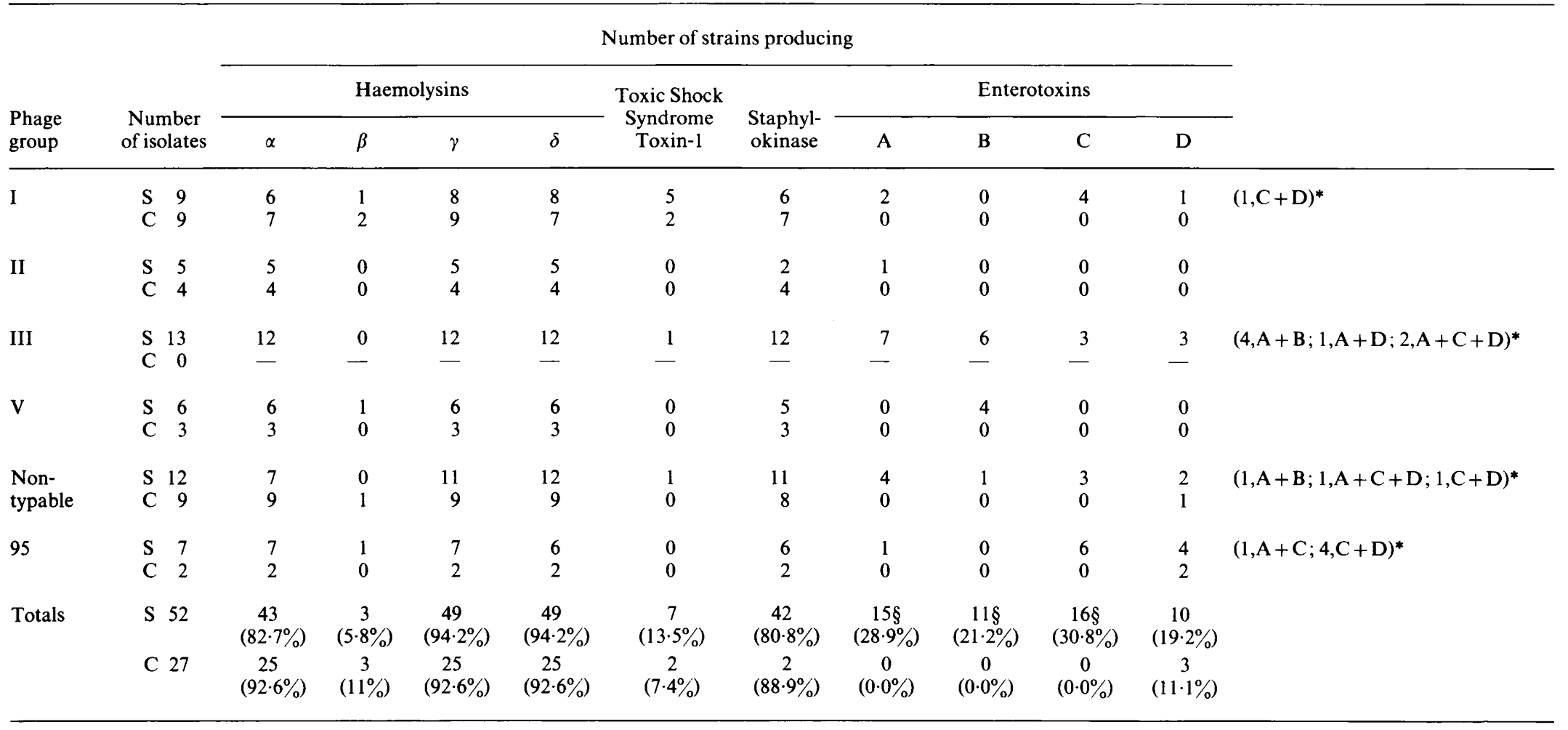

$\mathrm{S}=$ septicaemia $; \mathrm{C}=$ carriage

*Refers to the number of individual isolates included in the totals which produced combinations of enterotoxins, as indicated.

$\S$ The differences in the incidence of production of enterotoxins $\mathrm{A}, \mathrm{B}$, and $\mathrm{C}$ by the septicaemia and carriage isolates were statistically significant $(\mathrm{P}<0 \cdot 01$; chi square test). 
Table II. Source of septicaemia for $52 \mathrm{~S}$. aureus isolates

Number of isolates originating in

\begin{tabular}{lccccccccc}
\cline { 3 - 7 } $\begin{array}{l}\text { Phage } \\
\text { group }\end{array}$ & $\begin{array}{c}\text { Number } \\
\text { of isolates }\end{array}$ & $\begin{array}{c}\text { Bone/ } \\
\text { joints }\end{array}$ & $\begin{array}{c}\text { Urinary } \\
\text { tract }\end{array}$ & $\begin{array}{c}\text { Respiratory } \\
\text { tract }\end{array}$ & Wound & Skin & $\begin{array}{c}\text { Intravascular } \\
\text { catheter }\end{array}$ & $\begin{array}{c}\text { Primary } \\
\text { infections }\end{array}$ & $\begin{array}{c}\text { Patient } \\
\text { mortality }\end{array}$ \\
\hline I & 9 & 0 & 1 & 0 & 0 & $2^{1}$ & $5^{1}$ & 1 & $2 / 9$ \\
II & 5 & 0 & 0 & $1^{1}$ & 0 & 1 & $1^{1}$ & 2 & $2 / 5$ \\
III & 13 & $3^{1}$ & 0 & 0 & $5^{5 \mathrm{M}}$ & 0 & $5^{1 \mathrm{M}}$ & 0 & $7 / 13 \ddagger$ \\
V & 6 & 0 & 0 & 0 & 1 & $1^{1}$ & 1 & $3^{1}$ & $2 / 6$ \\
Non- & 12 & 2 & 1 & $1^{1}$ & $2^{* 1 \mathrm{M}}$ & $1^{1 \mathrm{M}}$ & 3 & 2 & $3 / 12$ \\
typable & 7 & 0 & $1^{1}$ & $4^{1}$ & 0 & $1^{1}$ & 1 & 0 & $3 / 7$ \\
95 & 52 & 5 & 3 & 6 & $8 \dagger$ & 6 & 16 & 8 & $19 / 52$ \\
Total & & $(9 \cdot 6 \%)$ & $(5 \cdot 8 \%)$ & $(11 \cdot 5 \%)$ & $(15 \cdot 4 \%)$ & $(11 \cdot 5 \%)$ & $(30 \cdot 8 \%)$ & $(15 \cdot 4 \%)$ &
\end{tabular}

Superscript numbers refer to the number of isolates associated with patient deaths. $M=$ methicillin-resistant isolates associated with patient deaths.

*These two isolates were methicillin-resistant, only one of which was associated with patient death.

$\dagger$ The incidence of methicillin-resistant septicaemia isolates which originated from wound infections was statistically different from the incidence of methicillin-resistant strains which originated from a primary source, intravascular catheter, bone/joints, or respiratory tract $(\mathrm{p}<0.01)$, and from isolates which originated from the urinary tract or skin $(\mathrm{p}<0.05)$ (Fisher's Test).

$¥$ The incidence of phage-group III methicillin-resistant septicaemia isolates which were associated with patient deaths was significantly different $(\mathrm{p}<0.01)$ from the incidence of non-methicillin-resistant group III isolates which were associated with patient deaths (Fisher's Test).

deaths associated with non-methicillin-resistant phage-group III isolates (table II). Of the nine septicaemia patients infected with methicillinresistant isolates, eight died (table II).

The pattern of enterotoxin production by the septicaemia isolates in relation to the original source of infection reflected the phage group to which the isolates belonged (table II, figure). All eight of the septicaemia isolates which originated from a wound infection produced enterotoxins (SEA, SEB or SEA + SEB). Seven of these isolates were methicillin-resistant; of these, four produced SEA + SEB, two SEA and one SEB (figure). Ten $(62.5 \%)$ of the 16 septicaemia isolates which originated from an infected intravascular catheter produced one or more enterotoxin; SEC was the most frequently produced ( 7 out of 16 ), either alone or in combination with the other enterotoxins (figure). Three of the six isolates which originated from respiratory tract infections produced SEC + SED; all three isolates were of phage-type 95 (figure; table II).

\section{Discussion}

Many of the clinical features reported here have been described previously for $S$. aureus septicaemia (Grandsen et al., 1984). Patient mortality was high $(36.5 \%)$, the majority of cases were hospitalacquired $(67 \%)$, and an infected intravascular device was the most common source of septicaemia. Because many of the patients with septicaemia had underlying disease, or were undergoing chemotherapy, or were otherwise debilitated, it is impossible to correlate mortality or survival with various strain characteristics. However, comparison of the properties of the organisms which caused septicaemia with control strains from a healthy population is valid.

The frequency of production of $\alpha-, \beta$-, and $\delta$-lysin by both groups of isolates was similar and in agreement with previous reports of the incidence of production of these factors by clinical $S$. aureus isolates (Elek and Levy, 1950). There have been very few reports about the frequency of production of $S$. aureus $\gamma$-lysin, possibly due to the inhibition of this lysin by agar (Möllby, 1983; Carlson, 1986). However, in a recent study Clyne et al. (1988) reported that $\gamma$-lysin was produced by all of ten clinical $S$. aureus strains from a range of infections; this is in agreement with the findings of the present study in which $>90 \%$ of the septicaemia and nasal strains produced $\boldsymbol{\gamma}$-lysin (table I).

Christensson and Hedstrom (1986) recently reported frequencies of $58 \%$ and $24 \%$ for $\alpha$-lysin and $\delta$-lysin production, respectively, in $88 S$. aureus strains from clinical septicaemia. This contrasts with our study, in which frequencies in excess of $80 \%$ and $90 \%$, respectively, were recorded (table I). The reasons for the differences between the studies 


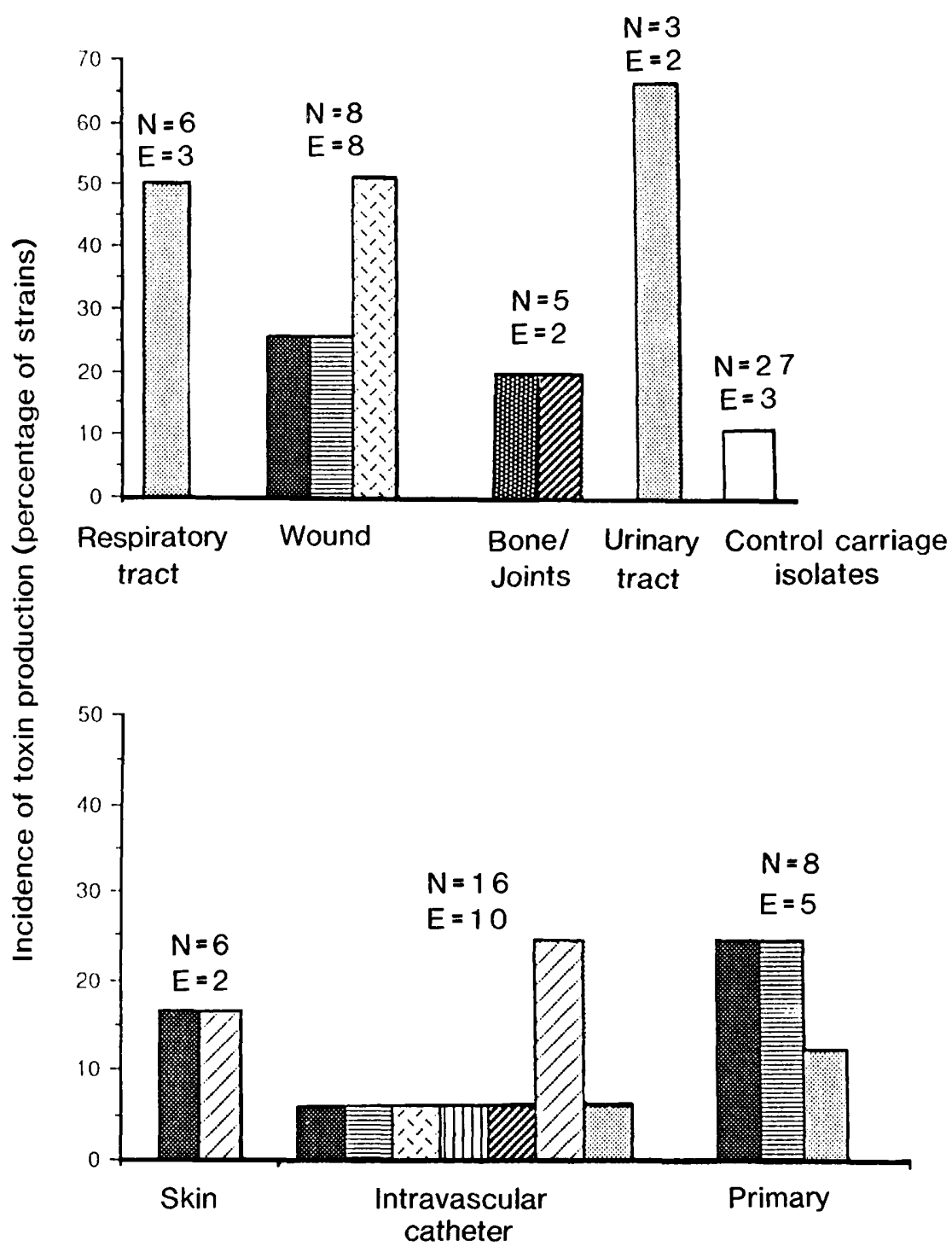

Figure. The incidence and pattern of enterotoxin production by septicaemia isolates in relation to source of septicaemia. $\mathrm{N}=\mathrm{The}$ number of septicaemia isolates which originated from each $S$. aureus infected source, as indicated. $E=T$ The number of isolates from each source category which produced enterotoxin. The primary source category refers to the isolates which caused septicaemia, the source for which could not be attributed to a focus of $S$. aureus infection previous to septicaemia. Enterotoxin production: $\mathrm{A}$, 目 $\mathrm{B}, \square \mathrm{C}, \square \mathrm{D}, \square \mathrm{A}+\mathrm{B}, \mathbb{\mathrm { A }}+\mathrm{C}$, 躍 $\mathrm{A}+\mathrm{D}, \square \mathrm{C}+\mathrm{D}, \mathbb{Z} \mathrm{A}+\mathrm{C}+\mathrm{D}$.

are unclear. In the present study the frequency of $\alpha$-lysin production by non-typable septicaemia isolates $(58 \%)$ was lower than by other phage groups. This is identical to the frequency for $\alpha$-lysin production reported by Christensson and Hedstrom (1986) for their non-typable septicaemia strains $(58 \%)$.

The frequency of production of TSST-1 by septicaemia and nasal isolates was similar, and in accordance with previous reports the majority of producers belonged to phage-group I (Todd et al.,
1978; Hayes et al., 1984). S. aureus Toxic Shock Syndrome (TSS) isolates have recently been reported to be poor $\alpha$-lysin producers, as have some non-TSS clinical strains which produce TSST-1 (Chow et al., 1982; Clyne et al., 1988). Our finding that although none of the TSST $-1^{+}$septicaemia isolates identified in this study were associated with TSS, only $66 \%$ of them produced $\alpha$-lysin, is in agreement with these reports.

Although only a minority of the septicaemia isolates $(12 \%)$ produced $\beta$-lysin, all of these were 
hospital-acquired. None of the 17 communityacquired-septicaemia strains produced $\beta$-lysin. This may be due to a higher incidence of carriage of $\beta$-lysin/staphylokinase double-converting prophages (Coleman et al., 1986). In support of this hypothesis, the frequency of staphylokinase production by hospital-acquired isolates $(74 \%)$ was significantly $(p<0.01)$ lower than that of the community-acquired strains $(94 \%)$.

The most unexpected finding of the present study was the highly significant $(\mathrm{p}<0.01)$ difference in the frequency of enterotoxin production by the septicaemia and nasal isolates (table I). The latter tended to be non-enterotoxigenic, apart from three strains that produced SED. In contrast, $63.5 \%$ of the septicaemia strains produced SEA, SEB, SEC and SED, either alone (except SED) or in various combinations (table I). There was some interesting correlation between the production of enterotoxins by septicaemia isolates and the particular phage groups, and these are in agreement with previous reports. The phage-group II septicaemia isolates, apart from a single strain, were non-enterotoxigenic, as found by Bergdoll (1985). Asheshov et al. (1977) reported that SEB was produced by $>50 \%$ of phage-group $\mathrm{V}$ isolates, which also did not produce any other enterotoxin. In this report, $66.6 \%$ of the phage-group V septicaemia strains produced SEB only (table I). Phage-type 95 septicaemia strains were the most frequent producers of enterotoxins in this study; six $(86 \%)$ out of seven produced SEC and four of these also produced SED. Several studies have revealed that the majority of SEA-producing $S$. aureus strains belong to phage-group III and this is particularly true of strains from cases of staphylococcal food poisoning (Parker, 1983). In the present study, $73 \%$ of SEAproducing isolates were divided between phagegroup III and the non-typable group as were the majority $(64 \%)$ of SEB-producing strains (table I).

The pattern of enterotoxin production by septicaemia isolates in relation to the original source of infection reflected the phage groups to which the strains belonged. The high incidence of production of enterotoxins A, B and particularly $A+B$ by septicaemia isolates which originated from wound infections, was due to the fact that the vast majority (7 out of 8) of these isolates were MRSA, all of which produced enterotoxins $\mathrm{A}, \mathrm{B}$ or $\mathrm{A}+\mathrm{B}$ (tables I and II, figure). Furthermore, the finding that the only enterotoxins produced by septicaemia isolates which originated from respiratory tract infections, were enterotoxins $\mathrm{C}+\mathrm{D}$ in combination (figure), correlated with the fact that the majority (4 out of 6 ) of isolates from this source belonged to phage type 95 (table II), most of which produced this combination of enterotoxins (table I).

Of the enterotoxin-producing septicaemia isolates, $27 \%$ were methicillin-resistant $S$. aureus strains (MRSA). Eight of the MRSA isolates were indistinguishable from the closely related Phenotype-II MRSA isolates which have been endemic in Dublin hospitals for the past decade (Coleman et al., 1985) and one MRSA strain belonged to a new group of MRSA isolates, Phenotype-III which were first isolated in Dublin in June 1985 and which are thought to have originated in Baghdad (Carroll et al., 1988). These isolates accounted for $47 \%$ of the total SEA-positive, $47 \%$ of the total SEBpositive and $100 \%$ of the total SEA + SEB-positive septicaemia isolates. There have been few reports of enterotoxin production by endemic hospital MRSA strains but recently Duckworth and Oppenheim (1986) reported the isolation of two separate epidemic MRSA strains in a London hospital which produced SEA and SEB respectively. $\mathrm{Nu}-$ merous episodes of nosocomial infection due to MRSA have been reported from many centres including Ireland, the UK, Europe, the USA and Australia during the past 5 years (Lyon and Skurray, 1987). The capacity of these organisms to produce enterotoxins may be an important factor in their success as nosocomial pathogens. This suggestion may be particularly important in view of the high mortality associated with these organisms described in this paper. The very strong association between MRSA isolates and wound infections reported here (table II) also suggests that these organisms are primarily opportunist pathogens.

Apart from staphylococcal food poisoning, the significance of enterotoxins in the pathogenesis of $S$. aureus disease is unclear. However, staphylococcal enterotoxins are potent biologically active proteins, and have been shown to be responsible for a range of symptoms and effects both in vivo and in vitro, including shock, circulatory collapse, thrombocytopenia, erythroderma, non-specific $T$ cell mitogenicity, immunosuppression, inhibition of antibody production, mediator release, pseudoallergic reactions and cytoxicity towards various cell lines (Bergdoll, 1983; Lin and Rogers, 1986; Scheuber et al., 1987). Staphylococcal enterotoxins are often produced by $S$. aureus strains from patients with TSS, and SEB has been implicated as the cause of some cases (Crass and Bergdoll, 1986a). Crass and Bergdoll (1986b) recently reported that many TSS patients have lower levels of antibody to TSST- 1 and to staphylococcal enterotoxins A, B, and $\mathrm{C}$ than did a healthy control population; thus, individuals with low levels of antibodies to staphy- 
lococcal enterotoxins may be more susceptible to the effects of enterotoxins than normal individuals. In the present study, none of the septicaemia patients presented with signs or symptoms of TSS or staphylococcal food poisoning, but many of them were debilitated and it is likely that they were also vulnerable to the effects of staphylococcal enterotoxins.

The data reported here suggest that potentially fruitful avenues of research in the future should include the construction of $S$. aureus derivatives with defined deletions in the enterotoxin genes, and

\section{REFERENCES}

Arbuthnott J P 1983 Epidermolytic toxins. In: Easmon C S F, Adlam C (eds) Staphylococci and staphylococcal infections, Vol 2. Academic Press, London, pp 599-617.

Arbuthnott J P 1988 Toxic shock syndrome: a multisystem conundrum. Microbiological Sciences 5: 13-16.

Arvidson S O 1983 Extracellular enzymes from Staphylococcus aureus. In: Easmon C S F, Adlam C (eds) Staphylococci and staphylococcal infections, Vol 2. Academic Press, London, pp 745-808.

Asheshov E H, Coe A W, Porthouse A 1977 Properties of strains of Staphylococcus aureus in the 94, 96 complex. Journal of Medical Microbiology 10: 171-178.

Bergdoll M S 1983 Enterotoxins. In: Easmon C S F, Adlam C (eds) Staphylococci and staphylococcal infections, Vol 2. Academic Press, London, pp 559-598.

Bergdoll M S 1985 The staphylococcal enterotoxins-an update. In: Jeljaszewicz J (ed) The Staphylococci. Zentralblatt für Bakteriologie, Mikrobiologie und Hygiene, Suppl 6 , pp 247-254.

Blair J E, Williams R E O 1961 Phage typing of staphylococci. Bulletin of the World Health Organization 24: 771-784.

Burnette W N 1981 "Western Blotting": electrophoretic transfer of proteins from sodium dodecyl sulfate-polyacrylamide gels to unmodified nitrocellulose and radiographic detection with antibody and radioiodinated protein A. Analytical Biochemistry 112: 195-203.

Carlson E C 1986 A CO 2 -enhanced hemolytic activity of Staphylococcus aureus associated with toxic shock syndrome: inhibition by agar. Journal of Infectious Diseases 154: $186-188$

Carroll J D et al. 1988 A new methicillin- and gentamicinresistant Staphylococcus aureus in Dublin : molecular genetic analysis. Journal of Medical Microbiology 28: 15-23.

Christensson B, Hedstrom S A 1986 Biochemical and biological properties of Staphylococcus aureus septicaemia strains in relation to clinical characteristics. Scandinavian Journal of Infectious Diseases 18: 297-303.

Chow A W, Gribble M J, Bartlett K H 1982 Hemolytic activity of toxic-shock syndrome-associated Staphylococcus aureus. Journal of Infectious Diseases 146: 98.

Clyne M, de Azavedo J, Carlson E, Arbuthnott J P 1988 Production of gamma-hemolysin and lack of production of alpha-hemolysin by Staphylococcus aureus strains associated with toxic shock syndrome. Journal of Clinical Microbiology 26: 535-539.

Coleman D C et al. 1985 Susceptibility to antimicrobial agents and analysis of plasmids in gentamicin- and methicillin- comparison of these strains for virulence with their wild-type parental strains in animal models. These studies could be particularly valuable with methicillin-resistant strains, which have been a major cause of nosocomial infection in many countries over the past decade.

We acknowledge the support of the Irish Medical Research Council for a Hospital Infection Unit Programme grant and thank Dr. F. Falkiner and Dr. C. Smyth for useful discussions and comments, B. Carey for help with the manuscript and $\mathrm{Dr}$ Joyce de Azavedo for testing some of the isolates for TSST-1 production.

resistant Staphylococcus aureus from Dublin hospitals. Journal of Medical Microbiology 20: 157-167.

Coleman D C, Arbuthnott J P, Pomeroy H M, Birkbeck T H 1986 Cloning and expression in Escherichia coli and Staphylococcus aureus of the beta-lysin determinant from Staphylococcus aureus : evidence that bacteriophage conversion of beta-lysin activity is caused by insertional inactivation of the beta-lysin determinant. Microbial Pathogenesis 1: $549-564$.

Crass B A, Bergdoll M S $1986 a$ Toxin involvement in toxic shock syndrome. Journal of Infectious Diseases 153: 918 926.

Crass B A, Bergdoll M S $1986 b$ Involvement of staphylococcal enterotoxins in nonmenstrual toxic shock syndrome. Journal of Clinical Microbiology 23: 1138-1139.

Derbyshire J B 1961 Further immunological studies in experimental staphylococcal mastitis. Journal of Comparative Pathology and Therapeutics 71 : 146-158.

Devriese L A, Van De Kerckhove A 1980 A comparison of methods used for testing staphylokinase (fibrinolysin) production in staphylococcus strains. Antonie van Leeuwenhoek 46: 457-465.

Duckworth G J, Oppenheim B A 1986 Enterotoxin production in epidemic methicillin-resistant Staphylococcus aureus. Lancet 1 : 565-566.

Elek S D, Levy E 1950 Distribution of haemolysins in pathogenic and non-pathogenic staphylococci. Journal of Pathology and Bacteriology 62 : 541-544.

Freer J H, Arbuthnott J P 1972 Toxins of Staphylococcus aureus. In: Cohen J O (ed) The Staphylococci. Wiley Interscience, New York, pp 55-106.

Grandsen W R, Eykyn S J, Phillips I 1984 Staphylococcus aureus bacteraemia : 400 episodes in St. Thomas's Hospital. British Medical Journal 288: 300-303.

Gemmell C G 1982 The staphylococcus-new features 100 years after its discovery. Journal of Infection 4: 5-15.

Hayes P S, Graves L M, Feeley J C, Hancock G A, Cohen M L, Reingold A L, Broome C V, Hightower A W 1984 Production of toxic-shock-associated protein(s) in Staphylococcus aureus strains isolated from 1956 through 1982. Journal of Clinical Microbiology 20 : 43-46.

Kjems E 1963 Two variants of Staphylococcus aureus Wood 46 (NCTC 7121) differing in respect to alpha toxin production. Journal of Bacteriology 86: 1127-1128.

Lacey R W, Keyworth N, Lincoln C 1984 Staphylococci in the U.K.: a review. Journal of Antimicrobial Chemotherapy 14 Suppl D: 19-25.

Langley R 1979a Fisher's Test. In: Practical statistics simply 
explained, edn 2. Pan Education Statistics, London, pp 292-317.

Langley R $1979 b$ Yates' $\chi^{2}$ Test. In: Practical statistics simply explained, edn 2. Pan Education Statistics, London, pp 285-291

Lin Y-S, Rogers T J 1986 Inhibition of antibody production from the plasmacytoma cell line MOPC-315 by staphylococcal enterotoxin B-induced T-suppressor cells. Cellular Immunology 102: 299-306.

Lyon B R, Skurray R A 1987 Antimicrobial resistance of Staphylococcus aureus: genetic basis. Microbiological Reviews $51: 88-134$.

Maki D G 1981 Nosocomial bacteremia. An epidemiological overview. American Journal of Medicine 70: 714-732.

Möllby R 1983 Isolation and properties of membrane damaging toxins. In: Easmon C S F, Adlam C (eds) Staphylococci and staphylococcal infections, Vol 2. Academic Press, London, pp 619-669.

Nolan C M, Beaty H N 1976 Staphylococcus aureus bacteremia. Current clinical patterns. American Journal of Medicine 60 495-500.

Novick R 1967 Properties of a cryptic high-frequency transducing phage in Staphylococcus aureus. Virology 33: 155-166.
Parker M T 1983 The significance of phage-typing patterns in Staphylococcus aureus. In: Easmon C S F, Adlam C (eds) Staphylococci and staphyloccal infections, Vol. 1. Academic Press, London, pp 33-62.

Russell R R B, Coleman D, Dougan G 1985 Expression of a gene for glucan- binding protein from Streptococcus mutans in Escherichia coli. Journal of General Microbiology 131 : 295-299.

Scheuber P H, Denzlinger C, Wilker D, Beck G, Keppler D, Hammer D K 1987 Staphylococcal enterotoxin B as a nonimmunological mast cell stimulus in primates: the role of endogenous cysteinyl leukotrienes. International Archives of Allergy and Applied Immunology 82: 289-291.

Shah M, Watanakunakorn C 1979 Changing patterns of Staphylococcus aureus bacteremia. American Journal of Medical Science 278: 115-121.

Shortle D 1983 A genetic system for analysis of staphylococcal nuclease. Gene 22: 181-189.

Todd J, Fishaut M, Kapral F, Welch T 1978 Toxic-shock syndrome associated with phage-group-I staphylococci. Lancet 2: 1116-1118. 